\title{
Electronic Spectra of Nitrosyl Chloride: A Reinvestigation Using Coupled Cluster and DFT Calculations
}

\author{
Iran da Luz Sousa, Pedro A. M. Vazquez \& Nelson H. Morgon
}

\section{Introduction}

Nitrosyl chloride $(\mathrm{Cl}-\mathrm{N}=\mathrm{O})$ can be observed at the strastophere and troposphere of the earth, being of interest in atmospheric chemistry. ${ }^{1,2}$ In particular, CINO can efficiently be photolyzed by ultraviolet (UV) radiation, releasing atomic chlorine radicals which are harmful for the ozone layer. ${ }^{3}$ The structure of nitrosyl chloride has been identified by various methods, including microwave, infrared, Raman and photochemistry spectroscopies .

$\mathrm{CINO}$ in the groud state has a bent molecular geometry and Cs symmetry. The valence electronic structure of CINO was investigated in early studies by photoelectron spectroscopy and theoretical calculations. ${ }^{4-7}$ The CINO electronic configuration of the frontier MOs is... (3a') $\left(12 a^{\prime}\right)\left(13 a^{\prime}\right)\left(4 a^{\prime \prime}\right)\left(14^{\prime}\right) \ldots, 3$ where single and double prime denote orbitals that are symmetric and anti-symmetric whith regard to the molecular plane, respectively. This system can be studied by rigorous computational methods because it has "only" 32 electrons. ${ }^{8}$

The elucidation of the decomposition process can be studied using molecular electronic spectra. The spectrum of nitrosyl chloride in gas phase was obtained by Goodeve and Katz.9 The UV/Vis region (2-7 eV) CINO exhibits a strong broad absorption band consisting of three contribuitions, where the most intense of them has a maximum at $6.3 \mathrm{eV}$.

The purpose of this work is to carry out calculations of the UV spectrum of nitrosyl chloride, based on current state-of-the-art methods. These methods include the approximate equation-of-motion coupled cluster with single-and-double excitations (EOM-CCSD).

\section{Methods}

The molecular structure of the $\mathrm{NOCl}$ system was optimized using program GAUSSIAN 09 program $^{10}$ at the CCSD or DFT levels. In the last case were employed B3LYP, CAM-B3LYP and PBE0 exchange/correlation functionals. The following basis sets were used: Dunning triple $\zeta$ aug-cc-pVTZ (ACCt) and quadruple $\zeta$ aug-ccpVQZ (ACCq).

Calculations of the vertical excited states were carried out at EOM-CCSD and TDDFT/CAM-B3LYP levels of theory. The CAM-B3LYP functional showed better performance that others conventional functional when applied for the excited electronic states.

\section{Results and Discussion}

In Table 1, the molecular structure of $\mathrm{NOCl}$, showing calculated and experimental values

Table 1. Geometrical parameters molecular structure of NOCl.

\begin{tabular}{llll}
\hline & $\mathrm{NO}(\AA)$ & $\mathrm{NCl}(\AA)$ & $\mathrm{NOC}\left({ }^{\circ}\right)$ \\
\hline CCSD/ACCt & 1.135 & 1.942 & 113.1 \\
CCSD/ACCq & 1.131 & 1.934 & 113.1 \\
CCSD(T)/ACCt & 1.141 & 1.979 & 113.4 \\
CCSD(T)/ACCq & 1.138 & 1.967 & 113.3 \\
B3LYP/ACCt & 1.127 & 1.997 & 114.1 \\
CAMB3LYP/ACCt & 1.125 & 1.952 & 113.4 \\
PBE0/ACCt & 1.126 & 1.952 & 113.8 \\
& & & \\
\hline Exp. $^{11}$ & 1.14 & 1.97 & 113.3 \\
\hline
\end{tabular}


All theoretical results give geometrical parameters closer to experimental values. The CCSD(T)/ACCt results provided a better performance and these results are in Fig. 1.

\section{$\operatorname{CCSD}(\mathrm{T}) / \mathrm{ACCt}$}

\section{Experiment}

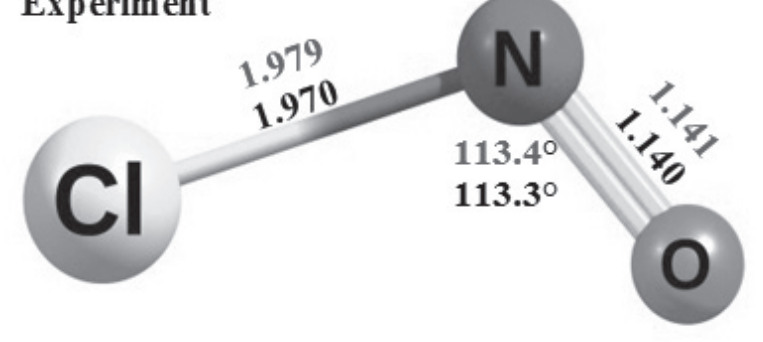

Figure 1. Molecular structure of nitrosyl chloride.

The result of the UV spectrum for singlet and triplet states is summarized in Table 2. The UV spectrum of $\mathrm{NOCl}$ in the gas phase shows a two very weak bands at $2.06 \mathrm{eV}$ (oscillator strength $\left.\mathrm{f}=10^{-5}\right), 2.64 \mathrm{eV}\left(\mathrm{f}=9 \times 10^{-}\right.$ $\left.{ }^{5}\right)$, a shoulder at $3.72 \mathrm{eV}\left(\mathrm{f}=10^{-3}\right)$ and a very strong band at $6.30 \mathrm{eV}(\mathrm{f}=0.5)$.

Table 2. Computed transition energies (in eV) and oscillator strength of $\mathrm{NOCl}$ employed different methodologies.

\begin{tabular}{|c|c|c|c|c|}
\hline State & \multicolumn{2}{|c|}{$\begin{array}{l}\text { EOM-CCSD/ } \\
\text { aug-cc-pVQZ }\end{array}$} & \multicolumn{2}{|c|}{$\begin{array}{l}\text { CAM-B3LYP/ } \\
\text { aug-cc-pVQZ }\end{array}$} \\
\hline \multicolumn{2}{|c|}{$\Delta \mathbf{E}$} & f & $\Delta \mathbf{E}$ & f \\
\hline $13 \mathrm{~A}^{\prime \prime}$ & $\begin{array}{c}2.19 \\
(2.06)^{\mathrm{a}}\end{array}$ & $0\left(10^{-5}\right)^{\mathrm{a}}$ & 1.76 & 0 \\
\hline $11 \mathrm{~A}^{\prime \prime}$ & $\begin{array}{c}2.77 \\
(2.64)\end{array}$ & $10^{-4}\left(9 \times 10^{-5}\right)$ & 2.71 & $10^{-4}$ \\
\hline $21 \mathrm{~A}^{\prime \prime}$ & $\begin{array}{c}4.49 \\
(3.72)\end{array}$ & $7 \times 10^{-4}\left(10^{-3}\right)$ & 4.05 & 0 \\
\hline $21 \mathrm{~A}^{\prime}$ & 4.77 & $3 \times 10^{-4}$ & 4.23 & $4 \times 10^{-4}$ \\
\hline $31 \mathrm{~A}^{\prime}$ & 4.87 & $6 \times 10^{-4}$ & 4.99 & $1.4 \times 10^{-4}$ \\
\hline $31 \mathrm{~A}^{\prime \prime}$ & 4.93 & $3 \times 10^{-4}$ & 5.07 & $3 \times 10^{-4}$ \\
\hline $41 \mathrm{~A}^{\prime}$ & $\begin{array}{c}6.49 \\
(6.30)\end{array}$ & $0.57\left(5 \times 10^{-1}\right)$ & 6.61 & 0.45 \\
\hline $51 \mathrm{~A}^{\prime}$ & $\begin{array}{c}8.51 \\
(8.26)\end{array}$ & $5 \times 10^{-2}$ & 8.14 & $6.8 \times 10^{-2}$ \\
\hline
\end{tabular}

${ }^{a}$ Experimental results (in parentheses) ${ }^{9}$.
The calculations EOM-CCSD/ACCq overestimates of excitation energy experimental. This methodology produced intensities comparable to the experiment. The energy of the bands in the CAM-B3LYP/ACCt simulation agrees quite well with experiment, although it overestimates at first and last excitation energy.

The calculated $41 \mathrm{~A}^{\prime}$ state, probably correspond to the most intense component of the experimental band. The functional CAM-B3LYP estimates this energy 6.61 $\mathrm{eV}(\mathrm{f}=0.45)$ and the energy transition calculated using equation-of-motion coupled cluster is $6.49 \mathrm{eV}(\mathrm{f}=0.57)$. Both methods describe this electronic transition.

The best description for an electronic state few studies in literature, $5^{1} \mathrm{~A}^{\prime}$ state, also computed in this study. The experimental vertical excitation energy is $8.26 \mathrm{eV}\left(51 \mathrm{~A}^{\text {' }}\right.$ state). The energy calculated we found this transition is: $8.51 \mathrm{eV}(\mathrm{f}=5 \times 10-2)$ with EOM-CCSD/ACCq method and $8.14 \mathrm{eV}(\mathrm{f}=6.8 \times 10-2)$ using CAM-B3LYP functional.

\section{Conclusions}

The molecular and electronic structure of the nitrosyl chloride was investigated using density functional and coupled cluster methodologies. A good agreement was observed between $\operatorname{CCSD}(\mathrm{T}) / \mathrm{ACCt}$ calculations and experimental results.

The calculations EOM-CCSD/ACCq overestimates of excitation energy experimental. The CAM-B3LYP/ ACCq provides the best results of excitation energy for the second and last bands. Both methods describe well at the experimental intensities

\section{Acknowledgments}

The authors are grateful for the support given from the CAPES, FAPESP, CNPq and FAEPEX-UNICAMP.

\section{References}

1. T. J. Luick, R. W. Heckert, K. Schulz and R. S. Disselkamp, J. Atmos. Chem. 32, 315, (1999).

2. P. Q. Wang, Modern Physics Letters., B, 26, 1250065, (2012).

3. S. Luca et al, Phys. Chem. Chem. Phys., 17, 9040, (2015).

4. D. C. Frost, S. T. Lee, C. A. McDowell, N. P. C. Westwood, J. Electron Spectrosc. Relat. Phenom., 7, 331, (1975).

5. M. I. Abbas, J. M. Dyke, A. Morris, J. Chem. Soc., Faraday Trans., 72, 814.(1976). 
6. E. Gilberg, W. Schatzl, H. W. Schrenk, Chem. Phys., 13, 115, (1976).

7. T. Yamashita, S. Kato. J. Chem. Ph., 121, 2105, (2004).

8. J. M, Kiera, J. A. Milkiewicz, B. J. Whitaker, A. G. Sage, Alan, A. G. Worth. ChemPhysChem, 14, 1439, (2013).

9. C. F. Goodeve, S. Katz, Proc. Roy. Soc. A., 172, 432, (1939).

10. http://www.gaussian.com

11. G. Cazzoli, C. Degli Esposti, P. Palmieri and S. Simeone, J. Mol. Spectrosc., 97, 165 (1983).

\section{Iran L. Sousa ${ }^{*}$, Pedro A. M. Vazquez \& Nelson H. Morgon $^{a}$}

anstituto de Química, Universidade Estadual de Campinas, CP 6154, 13084-862 Campinas-SP, Brasil

*E-mail: iran.sousa@iqm.inicamp.br 